\title{
Large haematoma in uterovesical pouch following vaginal delivery
}

\author{
Javed Ali , Pronamika Konyak \\ Correspondence: Dr Javed Ali, Associate Professor, Department of Obstetrics and \\ Gynaecology, Gauhati Medical College and Hospital, Guwahati-32, Assam, India; \\ e-mail: drjavedalighy@rediffmail.com
}

Distributed under Creative Commons Attribution-Share Alike 4.0 International.

\begin{abstract}
Puerperal haematomas following delivery pose a great threat to the patient and a challenge to the obstetricians. A 26 years old female with parity 2 attended at day 1 of puerperium following vaginal delivery in a periphery centre with anaemic and abdominal distension. The patient gave history of applying pressure over her abdomen during the birthing process. Intraoperatively, a large haematoma was seen in the uterovesical pouch (approx $20 \mathrm{~cm} \times 7 \mathrm{~cm}$ ) and drainage of haematoma was done. Post operative period was uneventful and the patient was discharged on day 5 post operatively.
\end{abstract}

Keywords: Pelvic hematoma, fundal pressure, vaginal delivery.

During pregnancy, the pelvic organs owing to the rich vascular supply are at a risk of trauma during the birth process. This may lead to haematoma formation. Puerperal haematomas occur in 1:300 to $1: 1500$ deliveries and rarely may pose as a life-threatening complication [1,2]. Puerperal genital hematomas are classified as either supralevator or infralevator hematomas. Supralevator hematomas though rarer pose a greater threat regarding management. Here we report a case of pelvic hematoma that had occurred following vaginal delivery in which fundal pressure was used and which necessitated a laparotomy.

\section{Case report}

A 26 years old female with parity 2 attended the emergency department of gynaecology, Gauhati
Medical College and Hospital (GMCH) at day 1 of puerperium following vaginal delivery in a periphery centre. The patient gave history of applying pressure over her abdomen during the birthing process. Following delivery her general condition deteriorated and so she was referred to GMCH. On admission, she was found to be anaemic with abdominal distension. However no bleeding was seen coming through the vagina. An ill defined mass was felt in the right hypochondriac region. Blood transfusion was given and an ultrasound performed. In the ultrasound, the uterine cavity was seen empty but the bladder was distended and a haematoma (approx $12 \mathrm{~cm} \times 7 \mathrm{~cm}$ ) was seen in the uterovesical pouch. Laparotomy was planned and the patient operated on. Intraoperatively, no rent was

Received: $2^{\text {nd }}$ July 2016. Accepted: $20^{\text {th }}$ September 2016.

Ali J, Konyak P. Large haematoma in uterovesical pouch following vaginal delivery. The New Indian Journal of OBGYN. 2017; 3(2): 111-3 


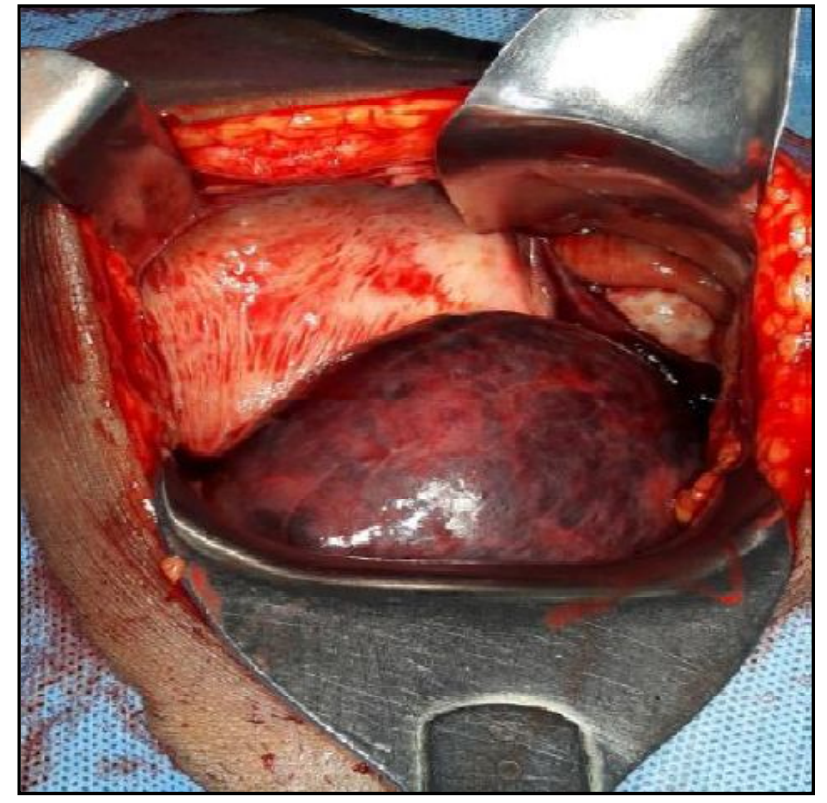

Figure1: Haematoma in uterovesical pouch

found in the uterus, but a large haematoma was seen in the uterovesical pouch (approx $20 \mathrm{~cm} \quad \mathrm{x} \quad 7 \mathrm{~cm}$ ) (Figure1). Tubes and ovaries were normal. Incision was made over the haematoma and 1 (one) kidney tray full of clots removed from it (Figure 2). Two drains were then placed, one in the uterovesical pouch and the other intraperitoneal. The uterovesical pouch was then sutured by interrupted stitches using vicryl and the

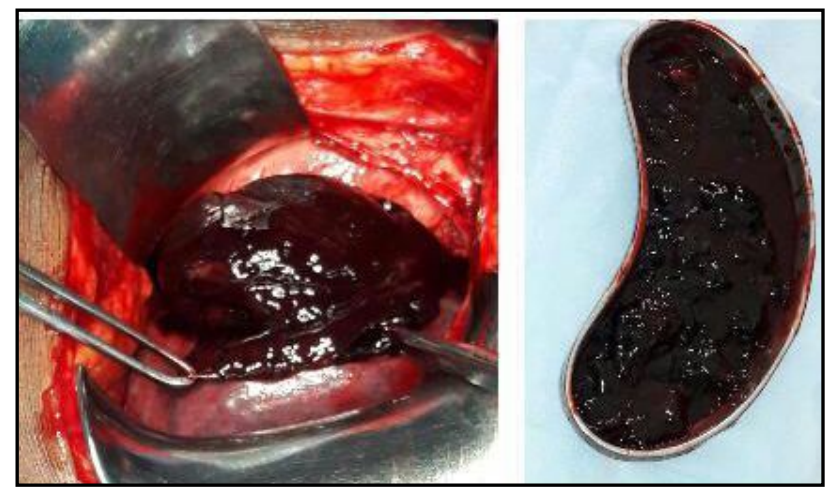

Figure 2: Clots drained out of the haematoma abdomen closed (Figure 3). Two more units of blood transfusion were given. Post operative period was uneventful and the patient was discharged on day 5 post operatively.

\section{Discussion}

In this rare pelvic haematoma case, a possible explanation for the haematoma could be the fundal/abdominal pressure which was applied at the time of delivery in the periphery centre which could have led to rupture of a vessel and subsequent haematoma formation. A high level of suspicion is warranted in such cases as clinical symptoms can be quite vague. Fundal pressure is one practice found in both traditional societies and in modern hospital obstetrics that may actually be harmful. Fundal pressure was used routinely in U.S. hospitals but its use has declined now. However, some do still use it and end up causing more harm than good. Listening to

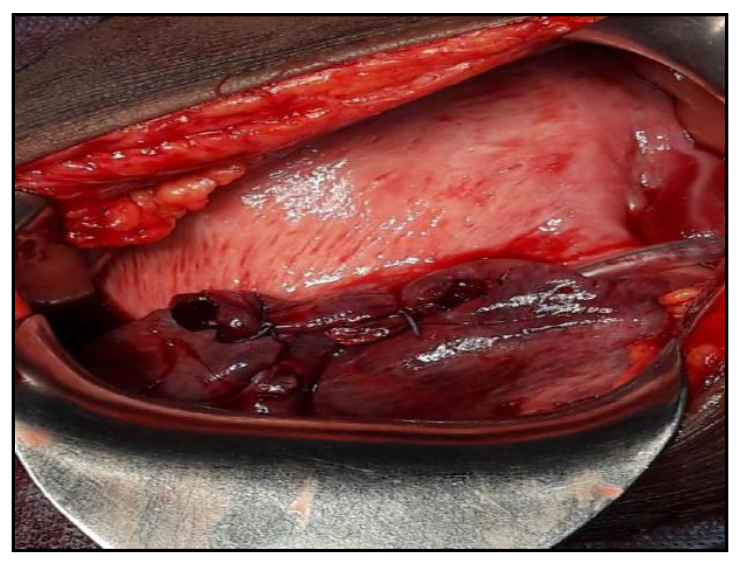

Figure 3: Drain left in uterovesical pouch and sutured

mothers II, a 2006 survey of birthing women in the United States, found that $17 \%$ of mothers reported having fundal pressure applied during their births. Much of the data about maternal-fetal injuries related to fundal pressure are not published for medical-legal reasons; however, anecdotal reports suggest that these risks exist [3]. Similar case of supralevator hematoma following vaginal delivery was also reported by Okafor 
$\mathrm{Cl}$ et al [4]. Kaya [5] reported a case of paravesical and broad ligament hematoma after vaginal delivery who presented with shock, which was successfully managed with internal iliac artery ligation. Muthulakshmi et al. [6] diagnosed a case with broad ligament hematoma after vaginal delivery as early as $3.5 \mathrm{~h}$ which was managed with uterine artery embolization. Singh et al. [7] reported a case with ischiorectal hematoma after vaginal delivery. In this case, the hematoma passed the levator ani barrier and extended to the supralevator area involving the broad ligament and retroperitoneal area. The source of bleeding could not be found and the hematoma was drained. Afterwards, surgicell (Ethicon) packs were applied to the retroperitoneal space and gauze roll packs were inserted into the vagina. Ten units of blood were administered to the patient.

\section{Conclusion}

Supralevator hematomas should be considered in patients who present with lower abdominal pain in absence of vaginal bleeding following vaginal delivery. Diagnosis becomes almost certain if associated with lump lower abdomen and any history of manipulation during delivery like fundal pressure. Ultrasound may be helpful for diagnosis though not conclusive. As fundal pressure use has seen to be more associated with maternal and fetal harm, it should be avoided at any cost and other simpler, safer alternatives used during labour instead.

\section{Conflict of interest: None. Disclaimer: Nil.}

\section{References}

1.Zahn CM, Yeomans ER. Postpartum hemorrhage: placenta accrete, uterine inversion, and puerperal hematomas. Clin Obstet Gynecol 1990; 33:422.

2. Villella J, Garry D, Levine G, et al. Postpartum angiographic embolization for vulvovaginal hematoma. A case report of two cases. J Reprod Med. 2001; 46:65.

3. Merhi Z01, Awonuga AO. The role of uterine fundal pressure in the management of the second stage of labour: a reappraisal. Obstet Gynaecol Surv. 2005; 60(9): 599603. PMID:16121114.

4. Okafor $\mathrm{Cl}$, Okafor CO, Nwankwo ME. Large supralevator puerperal haematoma following a normal delivery. Niger J Med. 2012; 21 (4): 472-3

5. Kaya B. Paravesical and broad ligament hematoma after vaginal delivery Case Rep. Perinat Med. 2015; 4(1): $17-20$.

6. Muthulakshmi B, Francis I, Magos A, Roy M, Watkinson A. Broad ligament haematoma after a normal delivery. J Obstet Gynaecol. 2003; 23: 669-70.

7. Singh J, Basu S, Aich A, Bhal PS. Spontaneous ischiorectal and retro-peritoneal haematoma after normal vaginal delivery. J Obstet Gynaecol. 2008; 28: 798-9.

\footnotetext{
Javed Ali $^{1}$, Pronamika Konyak ${ }^{2}$

${ }^{1}$ Associate Professor, Department of Obstetrics and Gynaecology, GMCH; ${ }^{2}$ Post Graduate Student, Department of Obstetrics and Gynaecology, GMCH.
} 